\title{
A abordagem socioconstrutivista na gestão escolar: uma parceria para a construção do conhecimento - estudo de caso em uma instituição escolar em Recife/PE
}

\begin{abstract}
RESUMO
O presente artigo aborda o tema Gestão do Conhecimento e enfatiza a importância de suas práticas dentro de uma Instituição Escolar em Recife que utiliza a abordagem de ensino e aprendizagem socioconstrutivista. Por meio de estudo de caso, buscou-se criar indicadores para a criação de comunidade de prática da Instituição, que já trabalha elementos voltados para a Gestão do Conhecimento, a partir do aspecto de fazer uso do conhecimento tácito. Teve como objetivo verificar a situação atual da Instituição educativa e, a partir da análise dos dados coletados pela aplicação do método Organizational Knowledge Assessment, e as três dimensões (pessoas, processos e sistemas), revelar uma parceria para a construção do conhecimento. $O$ resultado da pesquisa demonstrou que foi possível visualizar quais os pontos fortes e os fracos para a implantação de um plano de Gestão do Conhecimento, vinculada aos processos de trabalho. E que para a realização das atividades se faz necessário o comprometimento da alta gestão com o plano, ciente da importância da implantação de ferramentas da gestão do conhecimento não apenas no âmbito de suas práticas, mas no contexto educacional, atuando diretamente na condução do processo de diagnóstico junto aos colaboradores. Conclui-se que os resultados da pesquisa apresentam evidências consistentes das dimensões do conhecimento e orientações para o desenho do plano de Gestão do Conhecimento.
\end{abstract}

Palavras-chave: Gestão do Conhecimento. Conhecimento. Aprendizagem socioconstrutivista. Educação.

Andrea Medeiros Souza 


\section{INTRODUÇÃO}

O presente trabalho visa analisar a troca de conhecimentos entre professores de uma instituição educativa de confessionalidade cristã assumida de forma a propiciar o desenvolvimento do docente. $\mathrm{O}$ referencial teórico procurou apresentar o cenário das atividades desenvolvidas pela Instituição que utiliza a abordagem de ensino e aprendizagem socioconstrutivista abrangendo as características dos docentes, bem como, seu regime de trabalho e grau de escolaridade. Além disso, buscou apresentar os conceitos existentes sobre aprendizagem formal e informal e sobre a transmissão do conhecimento.

O compartilhamento de conhecimento pode colaborar para um melhor rendimento dos alunos no que se refere à aprendizagem e para a melhoria do desempenho do colégio em termos da gestão escolar. Este artigo considera os aspectos trabalhados pela Instituição e baseados nos quatro pilares da educação definidos no relatório da Comissão Internacional sobre a Educação no Século XXI, que são: aprender a conhecer; aprender a fazer; aprender a viver com os outros; aprender a ser.

Segundo Esteves, Pereira e Siano (2005,p.174) "a gestão escolar busca a autorregulamentação e a autonomia dos atores sociais, pelo exercício da participação, aliada ao profundo conhecimento de sua missão e de sua cultura". Esta participação está ligada à forma do aprendizado e à disseminação do conhecimento relacionadas com as relações ensino-aprendizagem.

Por meio de estudo de caso, busca-se criar indicadores para a formação de uma comunidade de prática para a Instituição, que já trabalha elementos voltados para a Gestão do Conhecimento, a partir do aspecto de fazer uso do conhecimento tácito. $\mathrm{O}$ artigo, com base na literatura, teve como objetivo verificar a situação atual da Instituição educativa e, a partir da análise dos dados coletados pela aplicação do método Organizational Knowledge Assessment(OKA), estabelecer as estratégias e as ações de execução, ou seja, elaborar o plano de GC do colégio e esclarecer os obstáculos enfrentados na explicitação e compartilhamento do conhecimento tácito baseado nos quatro pilares trabalhados pela Instituição educativa.

O método utilizado na pesquisa foi o OKA adaptado, que objetiva identificar a situação da Gestão do Conhecimento nas organizações de forma geral. O método dá suporte à elaboração de um plano de gestão do conhecimento e demonstra visão geral e integrada da situação da GC na organização.

Dada a importância de apontar as dimensões que precisam ser trabalhadas na Instituição educativa e a necessidade do reconhecimento do papel fundamental do Colégio no processo de criação do conhecimento, e de propor ações para melhorias dessas dimensões, este artigo apresenta como resultado os indicadores relacionados ao resultado das dimensões: pessoas, sistemas e processos. Este artigo mostra inicialmente uma revisão da literatura, os cuidados metodológicos utilizados durante a pesquisa, os resultados obtidos e as considerações finais referentes ao resultado do que se busca responder em relação ao objetivo inicial da pesquisa.

\subsection{Objetivo geral}

O objetivo geral foi verificar a situação atual da Instituição educativa em relação às práticas de Gestão do Conhecimento.

\subsection{Objetivos específicos}

De maneira a atingir o objetivo geral da pesquisa, foram estabelecidos os seguintes objetivos específicos: (a) determinar quais os indicadores de gestão do conhecimento podem ser recomendados para a criação de comunidade de prática da Instituição; (b) identificar na Instituição práticas de RH (pessoas), Processos e Sistemas de Gestão do Conhecimento.

\section{GESTÃO DO CONHECIMENTO}

A Gestão do Conhecimento atua em várias frentes de trabalho, e pode ser entendida como estratégia para gerar resultados para a organização, envolvendo processos organizacionais, pessoas e tecnologias.

Desta forma, o novo conhecimento é construído a partir da interação entres os conhecimentos tácitos e explícito.

\subsection{Gestão do Conhecimento e conhecimento tácito}

As instituições de ensino são as organizações de máxima produção do conhecimento. Nas atividades diárias de ensino, os colégios têm que obter, armazenar, compartilhar, utilizar, produzir e gerenciar conhecimentos 
com objetivo de educar os alunos de forma eficaz e neste momento de mudanças vertiginosas é preciso trabalhar a importância do conhecimento tácito.

Kidwell, Linde e Jhonson (2000) consideram que o conhecimento tácito é aquele contido na mente das pessoas, na forma de experiências, competências, habilidades práticas, ideias, crenças e valores pessoais.

As organizações que tem sucesso na gestão do conhecimento são susceptíveis de ver o conhecimento como um ativo e desenvolver normas e valores organizacionais, que suportam a criação e partilha de conhecimento (ROWLEY, 2000).

O Colégio Formação é uma instituição educativa, que visa proporcionar ao educando, através da vivência comunitária no ambiente de ensino e aprendizagem, formação integral. Este colégio nasceu no ano de 2005 no Cordeiro, bairro do Recife, atendendo as crianças da Educação Infantil com o objetivo de educar na busca por um mundo melhor. Desde então, desenvolve um trabalho onde a formação de cada educando é prioridade, para que eles possam atuar de maneira consciente, crítica e participativa na sociedade.

A metodologia utilizada busca a reflexão e elaboração do saber. Oferece uma diversidade de atividades inclusive o ensino de libras para a inclusão de verdade, garantindo a aprendizagem de todos os alunos. Como a Educação inclusiva compreende a Educação especial, dentro das várias atividades regulares do Colégio Formação existe um espaço para todos os alunos visando trabalhar as diferenças. As mudanças nos processos de negócio da Organização são de iniciativa da Diretora Pedagógica do Colégio.

O conceito de Educação inclusiva rompe "com o conceito de um desenvolvimento curricular único, com o conceito de aluno-padrão estandardizado, com o conceito de aprendizagem como transmissão, de escola como estrutura de reprodução" (RODRIGUES, 2003, p. 99).

Neste sentido, o processo de ensino-aprendizagem ganha uma nova postura, onde docentes e discentes aprendem em conjunto para a geração do conhecimento.

Alguns autores como Von Krogh, Nonaka e Aben (2001) dizem que os processos de criação e transferência determinam a evolução de um domínio; a escolha estratégica consiste em alcançar um equilíbrio entre domínios novos e existentes, processos e objetivos da firma. Deste modo, a empresa deve alocar recursos a domínios e processos de conhecimento.

Para que sejam trabalhados projetos de Gestão do Conhecimento a instituição educativa deverá criar, capturar, assimilar e disseminar o conhecimento. Esta interação ocorre por meio de quatro processos (Quadro 1).

Quadro 1-Conhecimento tácito X Conhecimento Explícito

\begin{tabular}{|c|c|c|}
\hline Conhecimento Tácito & Conhecimento Tácito & Conhecimento Explícito \\
\hline Conhecimento Explícito & $\begin{array}{c}\text { SOCIALIZAÇÃO } \\
\text { (interações e brainstorming) }\end{array}$ & $\begin{array}{c}\text { EXTERNALIZAÇÃO } \\
\text { (diálogo) }\end{array}$ \\
\hline $\begin{array}{c}\text { INTERNALIZAÇÃO } \\
\text { (aprender fazendo) }\end{array}$ & $\begin{array}{c}\text { COMBINAÇÃO } \\
\text { (troca de informações explícitas) }\end{array}$ \\
\hline
\end{tabular}

Fonte: Nonaka e Takeuchi (1997, p. 67).

Ao fazermos uma análise do Quadro 1 e da instituição educativa podemos indicar que a própria atividade produtiva pode ser organizada em torno do aprendizado relacionadas às atividades diárias de ensino. Uma das atividades que pode ser desenvolvida é a chamada comunidade de prática e repositório de conhecimento estruturado.

O termo comunidade de prática (CoP) foi cunhado porWenger (1998) para denominar grupos de pessoas que interagem, aprendem juntos, constroem relacionamentos pessoais e desenvolvem um senso de pertencimento e compromisso mútuo. Terra e Gordon (2002, p. 77) afirmam que "o ambiente virtual da comunidade de prática serve como uma plataforma de hipermídia para troca e armazenamento de arquivos, sejam eles imagens, sons, vídeos ou textos". As comunidades de práticas propiciam às organizações troca das melhores práticas, lições aprendidas, facilitam o benchmarking, dão visibilidade à expertise dos participantes, entre outras.

Uma das práticas para a Gestão do Conhecimento são os chamados "mecanismos de colaboração", onde se inserem as comunidades de práticas, que são apresentadas como:

Ferramentas que objetivam fortificar as relações e desenvolver o pensamento compartilhado. Compreendem as comunidades de práticas, construídas a partir de redes de pessoas que compartilham interesses em comum e aprendizado em uma específica área de conhecimento em um determinado período de tempo; conjuntos de ações de aprendizado, que consistem fundamentalmente em pequenos grupos de trabalho relacionados a assuntos complexos; técnicas dos seis chapéus pensantes (metodologia que objetiva confrontar os problemas por meio de diferentes pontos de vista); tecnologias 
sociais, compostas por dispositivos de comunicação móvel e plataformas web (e-learning, serviços de mensagens, espaços de trabalho virtual, wiki, blogs). (KURTZ, 2011, p. 70).

As comunidades de práticas são ferramentas colaborativas, que podem ser desenvolvidas e compartilhadas na criação de aplicações web mais dinâmicas e interativas e é um instrumento também de disseminação do conhecimento tácito, na medida em que as redes de pessoas se interligam e trocam informações e conhecimento das melhores práticas (sucessos obtidos e erros identificados para oportunidades de melhorias), registradas num banco de dados para posterior utilização.

Já os repositórios de conhecimento estruturado, são segundo Davenport e Prusak (2003), categorizados e com palavras-chave para facilitar a consulta e pesquisa dos usuários. Como exemplos de repositório podemos citar documentos sobre projetos e produtos, desempenho dos funcionários, projetos de pesquisa, mensagens eletrônicas formais, informações sobre clientes/consumidores.

\subsection{Aprendizagem socioconstrutivista na Gestão do Conhecimento}

A Instituição utiliza a abordagem de ensino e aprendizagem socioconstrutivista. Nesta perspectiva, o professor tem o papel de mediador, estimulando a criança a refletir mais e a fazer parte da construção do seu próprio aprendizado. Todo processo é construído considerando o conhecimento prévio, desenvolvimento e ritmo de cada educando. É priorizado no Projeto Político Pedagógico o compromisso social de contribuir com o processo de formação dos alunos e o seu desenvolvimento integral, considerando os aspectos intelectuais e emocionais.

Lins (2003) diz que a abordagem construtivista preconiza que todo processo de aprendizagem é um processo de construção, ou seja, de um lado o mestre e de outro o aprendiz. No construtivismo, a abordagem de socialização do conhecimento acontece a partir de experiências concretas, contextualmente significativas, no qual os aprendizes possam buscar os seus padrões e os mestres internalizem sem resistências as suas experiências. Parte-se da ideia que sempre existe uma possibilidade de representarmos as nossas experiências: modelos científicos explicativos, narrativas, contar estórias, linguagem, filmes, etc. O conhecimento é construído a partir da interação com o seu meio.

\subsubsection{Piaget e Vygotsky: Teorias Construtivistas em discussão no contexto da Gestão do Conhecimento}

Lins (2003) diz ao tratar das teorias construtivistas que a teoria de Piaget prioriza a interação entre sujeito e objeto e destaca que o crescimento cognitivo se dá a partir da ação do indivíduo sobre o objeto de seu conhecimento, foca na transformação. Na abordagem socioconstrutivista de Vygotsky (1989), verifica-se a interação com o meio social, a cultura e a linguagem que exercem forte influência sobre a aprendizagem e foca na transmissão; a aprendizagem tem um papel fundamental para o desenvolvimento do saber, do conhecimento. Todo e qualquer processo de aprendizagem é ensino-aprendizagem, incluindo aquele que aprende, aquele que ensina e a relação entre eles.

Segundo Vygotsky (1989), as interações sociais são as principais desencadeadoras do aprendizado; neste sentido a Gestão do Conhecimento pode ser entendida na concepção da colaboração que se apoia no processo de internalização para a apropriação de informações para o indivíduo (aluno e/ou professor) e no processo de construção do conhecimento criando condições de apropriações e reelaborações do conhecimento.

Piaget (1972) pretendia transmitir que em todos os níveis o conhecimento envolve sempre significado, organização e implicação, onde "o ideal da educação, não é aprender ao máximo [...] mas é antes de tudo aprender a aprender; é aprender a se desenvolver e aprender a continuar a se desenvolver depois da escola" (PIAGET, 1972, p. 32).

Neste sentido D'Ávila (2006, p. 91) diz que"a teoria construtivista oferece subsídios valiosos à compreensão da aprendizagem como um processo construtivo e significativo".

Vale destacar que a aquisição do conhecimento não pode ser confundida com a simples transmissão do conhecimento.

\section{O MÉTODO ORGANIZATIONAL KNOWLEDGE ASSESSMENT}

Segundo o método OKA, a Gestão do Conhecimento impacta e depende, fundamentalmente, dos três elementos que compõem uma organização: Pessoas, Processos e Sistemas. Para cada um destes elementos existe uma série de dimensões do conhecimento, perfazendo um total de 14. "A organização deve esforçarse para quantificar sua capacidade para identificar informação, conhecimento, experiência e intuição por meio das Pessoas, Processos e Sistemas para alcançar seus objetivos e gerar valor" (FONSECA, 2006, p. 3). A arquitetura do método OKA está apresentada na Figura 1. 
Figura 1 - Arquitetura do método OKA

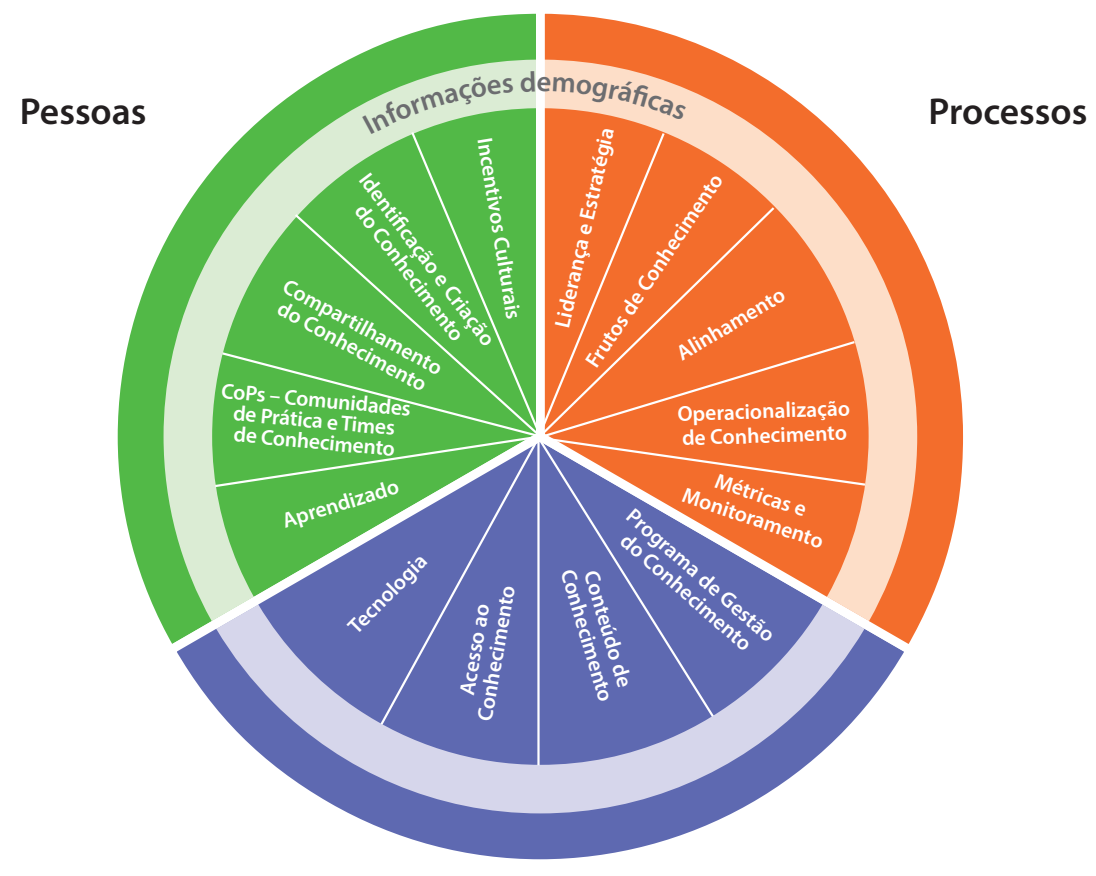

Sistemas

Fonte: Traduzido de Fonseca (2006, p. 4)

As dimensões - pessoa, processos e sistemas - são apresentadas no Quadro 2. Com as respostas do questionário aplicado, o método OKA fornece elementos que podem ser visualizados pela organização como a situação atual do processo de Gestão do Conhecimento.

Quadro 2 - Dimensões do Conhecimento pesquisadas pelo Método OKA.

\begin{tabular}{|c|c|}
\hline \multicolumn{2}{|c|}{ Dimensões do Conhecimento - OKA } \\
\hline Incentivos culturais & $\begin{array}{c}\text { Pessoas } \\
\text { São as atitudes culturais implícitas e explícitas, as crenças e os } \\
\text { incentivos que existem dentro da organização para formar, criar e } \\
\text { apoiar o uso dos ativos intelectuais para a obtenção de seus objetivos; }\end{array}$ \\
\hline $\begin{array}{c}\text { Identificação e criação } \\
\text { de conhecimento }\end{array}$ & $\begin{array}{c}\text { Capadade da organização em identificar e criar } \\
\text { conhecimento, objetos de suas metas; }\end{array}$ \\
\hline $\begin{array}{c}\text { Compartilhamento } \\
\text { de conhecimento }\end{array}$ & $\begin{array}{c}\text { Capacidade da organização em compartilhar conhecimento para } \\
\text { permitir o alcance dos seus objetivos }\end{array}$ \\
\hline $\begin{array}{c}\text { Comunidades de prática e times } \\
\text { de conhecimento: }\end{array}$ & $\begin{array}{c}\text { Visa identificar a existência de comunidades e equipes que } \\
\text { influenciem a solução de problemas, a fim de possibilitar o } \\
\text { alcance dos seus objetivos; }\end{array}$ \\
\hline Aprendizado & $\begin{array}{c}\text { Capacidade e habilidade da organização para construir capital } \\
\text { humano por meio de treinamento ou de outras atividades dirigidas, } \\
\text { com vistas ao aprimoramento do conhecimento. }\end{array}$ \\
\hline
\end{tabular}




\begin{tabular}{|c|c|}
\hline \multicolumn{2}{|r|}{ Processos } \\
\hline Liderança e estratégia & $\begin{array}{l}\text { Verifica a adoção e execução da disciplina de gestão do conheci- } \\
\text { mento como princípio gerencial, pelos líderes da organização; }\end{array}$ \\
\hline Fluxos de conhecimento & $\begin{array}{l}\text { Analisa como o conhecimento flui na organização, incluindo } \\
\text { sua captura, armazenamento e disseminação; }\end{array}$ \\
\hline $\begin{array}{l}\text { Operacionalização do } \\
\text { conhecimento }\end{array}$ & $\begin{array}{c}\text { Capacidade da organização em internalizar nos seus } \\
\text { processos e negócios o conhecimento gerado dentro da } \\
\text { organização (incluindo o desenvolvimento de novos produtos, } \\
\text { marketing e outros). Trata-se do feedback da real aplicação } \\
\text { do conhecimento nos negócios, e em decorrência, os resulta- } \\
\text { dos advindos para a organização; }\end{array}$ \\
\hline Alinhamento & $\begin{array}{c}\text { Efetividade com que os objetivos do Programa de Gestão do } \\
\text { Conhecimento e seus resultados satisfazem os objetivos e as } \\
\text { metas organizacionais; }\end{array}$ \\
\hline Métricas e monitoramento & $\begin{array}{l}\text { Capacidade da organização em se avaliar, no que tange ao } \\
\text { gerenciamento dos ativos intelectuais, além de acompanhar e } \\
\text { identificar melhores práticas, informações externas, e aprendizado, } \\
\text { que possam gerar valor para a organização, transformando-a; }\end{array}$ \\
\hline \multicolumn{2}{|r|}{ Sistemas } \\
\hline Tecnologia & $\begin{array}{l}\text { Existência e capacidade de infraestrutura tecnológica, que } \\
\text { permitam a gestão do conhecimento e o compartilhamento de } \\
\text { melhores práticas; }\end{array}$ \\
\hline Acesso ao conhecimento & $\begin{array}{l}\text { Capacidade e infraestrutura existente, que permitam que os } \\
\text { stakeholders acessem e compartilhem os ativos intelectuais da } \\
\text { organização nos seus sistemas ou com outras pessoas; }\end{array}$ \\
\hline Conteúdo de conhecimento & $\begin{array}{l}\text { Tipos de ferramentas que a organização produz ou executa } \\
\text { para gerenciar a informação; }\end{array}$ \\
\hline $\begin{array}{l}\text { Programa de Gestão } \\
\text { do Conhecimento }\end{array}$ & $\begin{array}{l}\text { Como o Programa de Gestão do Conhecimento está construí- } \\
\text { do dentro da empresa: sua natureza, seu desenho e capacida- } \\
\text { de para envolver pessoas, unidades, grupos, etc. }\end{array}$ \\
\hline
\end{tabular}

Fonte: Fonseca (2006, p. 5).

O diagnóstico utilizando o método OKA está voltado para a avaliação da capacidade de ampliação dos ativos intelectuais através dos elementos de pessoas, processos e sistemas, e estas dimensões são importantes na geração do diferencial competitivo e atingimento dos objetivos organizacionais.

\section{PROCEDIMENTOS METODOLÓGICOS}

A pesquisa envolveu a condução de um estudo de caso, apoiada em entrevista semiestruturada. Para a elaboração do diagnóstico, foi realizada uma pesquisa de campo, pois se trata de uma investigação empírica em uma instituição onde ocorre um fenômeno (GIL, 2006; VERGARA, 2007), uma vez que buscou-se analisar as atividades de GC desenvolvidas no Colégio Formação, com o propósito de aplicação de um plano de ação a partir dos resultados obtidos.

Metodologicamente este estudo caracteriza-se como empírico. De acordo com Triviños (1990), trata-se de uma pesquisa exploratória, de cunho descritivo por permitir que o investigador aumente a sua experiência em torno de determinada circunstância.

Como fontes de pesquisa bibliográfica, foram utilizados livros, dissertações, artigos de periódicos; as fontes de informação foram as bases de dados: Pergamum e Scientific Eletronic Library Online Scielo. As palavraschave utilizadas nas buscas, como critério para subsidiar a pesquisa foram educação, gestão do conhecimento e construtivista.

O instrumento de coleta dos dados constituiu-se de uma entrevista, com três dimensões e 24 variáveis (assertivas e questões), pela ferramenta OKA adaptada. Antes do envio da entrevista, foram realizadas ligações e contatos por e-mails e uma visita ao Colégio Formação para conhecer a Instituição Educacional e apresentar e explicar à direção o objetivo da aplicação da ferramenta e seus benefícios. A coleta de dados ocorreu no início de abril de 2014. 
As perguntas do método OKA, tanto na versão completa quanto na simplificada, são pertinentes às três dimensões já citadas nas quais se baseia o método: pessoas, processos e sistemas.

A população desse estudo compreendeu a alta administração. O Colégio Formação é de porte de microempresa, e sua diretora tem especialização na área de Educação, e trabalha na Organização entre 05 e 10 anos. Foi implantada a disciplina de Libras em toda a escola, e criado pela direção um curso gratuito para os colaboradores, aos sábados, na própria escola, que busca selecionar currículos de profissionais que já tenham o curso de Libras.

Em relação ao item que trata de conversão dos conhecimentos tácito para o explícito, a articulação dos modelos mentais tácitos, em um tipo de mobilização, é importante na criação do conhecimento, na medida em que busca transformar o conhecimento individual em recursos disponíveis aos colaboradores do Colégio Formação que por meio da abordagem de ensino e aprendizagem socioconstrutivista busca criar elementos possíveis de serem compreendidas e assimiladas pelos colaboradores.

A alta administração estima que os profissionais do colégio Formação possuem funções cuja atividade lida com trabalho baseado em conhecimento, não manual e rotineiro. Trata-se de registro em sua forma primária, organizado para ser processado, armazenado e transferido.

\section{ANÁLISE DE RESULTADOS}

Na dimensão "Pessoas", verificou-se como a área se posiciona atualmente no que se refere à cultura, identificação, criação e compartilhamento do conhecimento e aprendizado. Para Teixeira Filho (2000) as organizações estão cada vez mais conscientes da importância da cultura relacionada aos resultados, e há um interesse muito grande atualmente em torno dos valores organizacionais. O futuro da função de Recursos Humanos ou Pessoas será o que se fizer dela, coletivamente, nas decisões e ações cotidianas e em seus desdobramentos. A pesquisa pôde inferir a criação de alguns indicadores, levando em consideração as respostas apresentadas pela alta gestão.

A direção informou que os colaboradores participam nas revisões sistemáticas dos processos organizacionais; neste caso é importante promover ambientes que estimulem o diálogo criativo, para solução de problemas ou mesmo compartilhamento do conhecimento tácito, além de criar harmonia de pensamentos e objetivos entre os colaboradores.

A alta gerência é influente sobre a cultura organizacional e se comunica com os colaboradores de forma mediana; e os colaboradores compreendem geralmente o quanto seu papel contribui para a performance da organização e o grau de receptividade da organização em relação a sugestões dos colaboradores é de aceitação.

A estrutura hierárquica é pouco influente na definição dos padrões de comunicação na organização.

A organização oferece treinamentos específicos para desenvolvimento de novas habilidades dos colaboradores e eles são incentivados a identificar conhecimentos que possam beneficiar/melhorar processos operacionais na Organização; as atividades de GC, conhecimento, habilidades e competências técnicas são as que mais influenciam a performance dos colaboradores.

Analisando as respostas pode-se dizer que o Colégio Formação está caracterizado como mediano no processo de identificação, compartilhamento e aprendizado em relação à Gestão do Conhecimento.

Ficou clara a preocupação com a definição de ferramentas que ajudem a divulgar informações e a disseminar o conhecimento, voltadas para a área de RH e Gestão do Conhecimento. Ulrich (1996, p. 8) apud Gaia e Bento (2011, p. 2), diz que "as práticas de RH são processos organizacionais que podem ampliar as competências individuais e as capacidades organizacionais". O setor de RH tem conhecimento sobre as competências de seus colaboradores e dos processos organizacionais, como também dos objetivos organizacionais.

Na dimensão "Sistemas", apesar de apresentar alguns itens críticos em relação à atuação, como por exemplo, o nível de classificação de comunicação, realizado por meio de sistemas on-line na organização é baixo; a organização não possui uma arquitetura de informação corporativa; a organização não possui registros ou arquivos visando a criação de uma memória corporativa; existem grupos de trabalho na organização, entretanto, não são utilizados regularmente para resolução de problemas; a organização não possui comunidades de prática, nem sistemas/repositórios de conteúdo. Entretanto, a direção informa que o conhecimento tácito é compartilhado através de treinamentos e oficinas e que a organização considera importante a recuperação de informação para que a maioria dos colaboradores realize suas tarefas diárias:

Se considerarmos a comunidade virtual orientada para a aprendizagem como uma organização formada por pessoas com interesse comum, que se sentem pertencentes a ela, e que estão dispostos a se relacionar com o propósito de aprender através da construção do 
conhecimento, a ocorrência da gestão do conhecimento nesta comunidade didaticamente orientada é desejável e os processos de gerenciamento devem ser desencadeados pelo mediador da comunidade. A intencionalidade didática do mediador exige dele um esforço no sentido de promover o gerenciamento de um ciclo que favorece a captação de informações, sua armazenagem e distribuição, para que as pessoas, quando em contato com o conteúdo digital disponível, possam construir conhecimento. (GOZZI,2012, p. 9).

O resultado apontado na pesquisa como baixo, relacionado ao nível de classificação de comunicação realizado por meio de sistemas on-line, pode ser trabalhado com a introdução e incentivo do uso das funcionalidades da tecnologia, demonstrando que elas não substituem o professor, mas modificam algumas de suas funções.

Schneider (2013) aponta o perfil de um novo professor e de como o respaldo da formação contribui para a preparação no trabalho com as TIC e acrescenta as novas possibilidades de utilização das mesmas. Para ele a Escola pode contribuir muito para o desenvolvimento desta aptidão adotando práticas de Aprendizagem colaborativa e os professores devem usar desses recursos para permitir que os alunos aprendam juntos com colegas da turma.

As práticas de GC cujo foco central é a base tecnológica e funcional servem de suporte à gestão do conhecimento organizacional; observa-se a necessidade de utilização de ferramentas de TI para utilização por parte dos docentes e discentes do colégio para a prática de disseminação de conhecimentos. Entretanto deve ser levado em conta o que sugerem:

O perfil adquirido pelos profissionais em instituições que realizam a Gestão do Conhecimento e fazem uso de suas ferramentas de auxílio também é diferenciado, o fluxo de informação ocorre de maneira acelerada, o que demanda alto grau de flexibilidade por parte das organizações, docentes e discentes. A capacitação destes grupos é ponto chave e influenciará diretamente no nível de usabilidade e adaptação frente às ferramentas utilizadas ao longo do processo de aprendizagem. (DRUZIANI et al., 2011, p. 453).

A infraestrutura tecnológica disponível não possui uma arquitetura de informação corporativa, ou seja, não contribui e não facilita a colaboração entre os colaboradores do Colégio Formação, não facilitando o acesso e a recuperação da informação e do conhecimento, por não possuir sistemas/repositórios de conteúdo.

Considerou-se o acesso aos repositórios como um ponto de atenção apontado na pesquisa. E o conteúdo de conhecimento que é registrado foi visto como uma oportunidade de melhoria.

A formação de comunidades de prática no Colégio Formação contribuirá para a promoção da criação de ambientes colaborativos, ou seja, ambiente virtual de aprendizagem (AVA) que, segundo Vasconcellos e Oliveira (2011), trabalham interação entre todos os envolvidos numa situação comunicativa, construindo conhecimento a partir da reflexão e da crítica e o elemento da interatividade que busca com a pedagogia mediada por computadores aprender com o outro.

Para pensar a aprendizagem colaborativa e interativa é interessante resgatar a teoria vygotskyana, pois nela trabalhar com o outro é fundamental para o desenvolvimento humano. Isto reforça a ideia de que AVAs que propiciem maior interação entre os sujeitos favorecem a aprendizagem (VASCONCELLOS; OLIVEIRA, 2011, p. 59).

Das respostas das dimensões do elemento "Sistemas", observa-se que a maioria dos resultados estão classificados como baixo; verifica-se que o Colégio Formação não possui um programa formal de Gestão do Conhecimento e ainda não possui uma infraestrutura tecnológica adequada à Gestão do Conhecimento.

Na dimensão"Processos", verificou-se que o grau de importância do conhecimento ou das informações nos processos de agregação de valor da organização é considerado muito importante. Entretanto, a organização apoia pouco a interação social que permita o compartilhamento de conhecimento tácito entre pessoas.

A informação ou o conhecimento é disseminado pela organização aos seus colaboradores por meio de reuniões realizadas pela alta gerência que considera a organização como possuidora de um sistema de gestão do conhecimento. Entretanto, informa que é baixo o grau que os sistemas de gestão estão integrados no fluxo de trabalho da organização com vistas a criar novos conhecimentos.

Em relação ao grau em que os processos de conhecimento são internalizados na organização, os princípios de GC são considerados nos incentivos e avaliações pessoais. Os tipos de conhecimentos (internos ou externos) criados na organização são: melhores práticas e lições aprendidas. Os tipos de conhecimentos e/ou informações capturados pela organização são: lições aprendidas, documentos sobre projetos e produtos; informações sobre 
Andrea Medeiros Souza; Diego Jacob Kurtz

clientes e dados relativos ao desempenho dos colaboradores. O conhecimento implícito/tácito é disseminado através de conversas informais entre colaboradores.

A Internet reflete a principal forma de armazenamento de conhecimento da organização. E o nível de efetividade dos sistemas de gestão do conhecimento em conectar as pessoas com sistemas de informação é pouco efetivo.

As fontes utilizadas para identificar os conhecimentos que a organização deseja coletar são: pesquisa pela internet, experiência de colaboradores e experiência de parceiros e as fontes de informação obtidas e usadas nos processos decisórios da organização são: melhores práticas, feedback de clientes, feedback de funcionários, lições aprendidas.

A organização não tem /ou não usa métricas de medição do conhecimento e não há uma estratégia de GC claramente articulada (i. e., escrita) para a organização que não tem métricas de medição do conhecimento.

Alguns dos aspectos da organização que devem ser ajudados significativamente por atividades relativas ao conhecimento (tais como compartilhamento de conhecimentos e operacionalização do conhecimento) são: habilidades para modificar estratégias ou enfoques de resolução de problemas, políticas e procedimentos organizacionais.

A direção considera que as atividades de GC (criação do conhecimento, armazenamento, disseminação) que concorrem para os objetivos explícitos da organização são essenciais para a performance do negócio e a liderança das atividades de gestão do conhecimento, considerada pela direção, é realizada basicamente pelo nível da alta gerência.

A direção da Escola considera também que as áreas que devem se beneficiar mais do programa de gestão do conhecimento ou de atividades de compartilhamento de conhecimentos são: desenho de processos organizacionais e criação de uma estratégia de comunicação com clientes e que um bom programa de GC da organização ajudaria os colaboradores a economizar tempo em seu trabalho e aumentar o valor das oportunidades de desenvolvimento profissional, assim como os processos organizacionais melhorariam significativamente.

Embora apontado pela alta gerência como um sistema de gestão do conhecimento,não existe uma aplicação dos conhecimentos nos negócios e processos operacionais do Colégio, e não existe uma integração desses processos e conhecimentos.

O Colégio Formação reconhece que há alguns problemas culturais e técnicos que precisam ser superados para que as práticas de GC sejam parte integrante dos processos individuais e organizacionais. A organização precisa identificar e melhorar seus processos essenciais.

Kurtz (2010, p. 2) diz que "considerando que a gestão do conhecimento é indispensável para a competitividade e sustentabilidade das organizações, o desafio está em desenvolver mecanismos que proporcionem a criação, disseminação e uso de conhecimento". A divulgação de experiência de GC por meio de mecanismos de comunicação interna pode ajudar na disseminação do conhecimento e na criação de processos para a receptividade das atividades e melhores práticas da Gestão do Conhecimento.

A gestão por processos objetiva decompor os processos de maneira que estes estejam de acordo com os objetivos estratégicos da empresa. Uma de suas premissas básicas está no fato de possibilitar o entendimento e a padronização das atividades criando mecanismos para identificar oportunidades de mudanças nos processos, buscando sempre maior produtividade e agilidade na sua execução. Neste sentido, compreender como acontece o fluxo de conhecimento em uma cadeia produtiva pode auxiliar a criação/modificação, disseminação/ difusão, uso/aplicação de conhecimento nesse contexto (KURTZ, 2011, p. 43).

Para De Toro e McCabe (1997, apud Sordi, 2008) a gestão por processos é uma estrutura gerencial que deve envolver todos os executores e pensadores enquanto projetam o trabalho, inspecionam seus resultados e redesenham seu sistema de trabalho para o alcance de melhores resultados.

O resultado da pesquisa subsidiou a criação de indicadores de GC para o Colégio Formação que são apresentados no Quadro 3. Os indicadores devem ser claros, ligados ao dia a dia, de fácil uso e entendimento. É importante rever processos para definição de ações voltadas para a implantação da Gestão do Conhecimento. 
Quadro 3 - Indicadores de GC para o Colégio Formação

\begin{tabular}{|c|c|c|}
\hline \multicolumn{2}{|c|}{ Indicadores/dimensões } & Exemplos \\
\hline Pessoas & $\begin{array}{l}\text { Indicadores não financeiros } \\
\text { que traduzem em capacidade, } \\
\text { atitudes e habilidades. }\end{array}$ & $\begin{array}{l}\text { Quantidade de acessos para a melhoria das habilidades } \\
\text { dos funcionários na internet realizados mensalmente; } \\
\text { Quantidade de tempo médio de resolução } \\
\text { de problemas; } \\
\text { Sugestões feitas versus sugestões implementadas. }\end{array}$ \\
\hline Sistemas & $\begin{array}{l}\text { Indicadores não financeiros } \\
\text { e financeiros que } \\
\text { traduzem na capacidade } \\
\text { de infraestrutura tecnológica } \\
\text { e os tipos de ferramentas } \\
\text { produzidos ou executados } \\
\text { para gerenciar a informação }\end{array}$ & $\begin{array}{c}\text { Quantidade de publicações dos funcionários e alunos } \\
\text { sobre práticas desenvolvidas pelo Colégio; } \\
\text { Divulgação através das mídias eletrônicas para } \\
\text { avaliar a quantidade de curtidas dos trabalhos } \\
\text { desenvolvidos e contribuições (medição do tempo } \\
\text { on-line e número de logins); } \\
\text { Número de mensagens enviadas e recebidas. }\end{array}$ \\
\hline Processos & $\begin{array}{l}\text { Indicadores que traduzem em } \\
\text { medidas quantitativas. }\end{array}$ & $\begin{array}{l}\text { Quantidade de processos mapeados no Colégio } \\
\text { (analisar os processos atuais); } \\
\text { Quantidade de treinamentos dos colaboradores } \\
\text { com práticas de GC realizados anualmente; } \\
\text { Número de comunidades de práticas criadas no } \\
\text { Colégio Formação; } \\
\text { Quantidade de contribuições úteis (dos alunos } \\
\text { e colaboradores) ao conteúdo da memória } \\
\text { organizacional do Colégio Formação. }\end{array}$ \\
\hline
\end{tabular}

Fonte: Primária (2015)

Os indicadores mostram as áreas onde existem oportunidades de melhoria no Colégio Formação, entretanto não é uma lista definitiva apenas exemplos para métricas de medição do conhecimento.

\section{CONCLUSÕES}

A utilização da versão simplificada do método OKA foi a alternativa encontrada para possibilitar maior adesão da direção do Colégio Formação à pesquisa, considerando as limitações de tempo e do cronograma de pesquisa.

Sugere-se que o plano de GC do Colégio Formação tome em consideração a capacitação dos profissionais relacionados à aprendizagem individual e organizacional, com habilidades para criar, adquirir, transferir conhecimento e modificar comportamento.

O objetivo inicial da pesquisa foi respondido em relação à verificação da situação atual da Instituição educativa a partir da análise dos dados coletados pela aplicação do método OKA que forneceu subsídios para sugestão de um plano de ação de GC e, assim, a criação de indicadores para as práticas de GC, inclusive a criação de comunidade de prática do Colégio Formação, conforme apresentado, com vista a revelar uma parceria para a construção do conhecimento.

A construção de redes sociais para o compartilhamento do conhecimento contribuirá para o desenvolvimento e sensibilização dos funcionários e alunos para iniciativas que propiciem melhorar a comunicação. Analisando a pesquisa percebe-se a necessidade de um investimento em um plano de comunicação para a implantação de projetos de GC. Um plano de comunicação bem elaborado e realizado poderá contribuir para iniciar um processo de colaboração e compartilhamento da alta gerência para os colaboradores de forma forte.

Uma prática que pode ser relevante para o plano de GC do Colégio Formação poderia ser a criação do Mapeamento do Conhecimento que trabalha a classificação, identificação e disponibilização de documentos, profissionais, ou banco de dados. Desta forma, o Colégio poderá mapear os conhecimentos estratégicos existentes, podendo verificar as lacunas que podem ser trabalhadas pela organização para as atividades de compartilhamento de conhecimentos relacionadas ao desenho de processos organizacionais e criação de uma estratégia de comunicação com clientes.

Destaca-se também que para o estabelecimento das estratégias e as ações de execuções para a elaboração do plano de GC do colégio é preciso investir algum esforço em identificar os impactos da gestão do conhecimento considerando cada dimensão estudada, e a partir deste item elaborar possíveis indicadores e analisar os processos de gestão orientados por esses indicadores.

Um dos obstáculos enfrentados na explicitação e compartilhamento do conhecimento tácito do Colégio 
é o não compartilhamento do conhecimento por meio da internet, que está relacionado à questão cultural da Instituição, daí a importância de algumas diretrizes da Gestão que deve ser levada em consideração para a implantação das práticas de GC.

Foi possível visualizar quais os pontos fortes e os fracos para a implantação de um plano de GC, vinculada aos processos de trabalho. Para a realização das atividades se faz necessário o comprometimento da alta gestão com o plano, ciente da importância da implantação de ferramentas da gestão do conhecimento não apenas no âmbito de suas práticas, mas no contexto educacional, atuando diretamente na condução do processo de diagnóstico junto aos colaboradores.

Uma das limitações do estudo foi a falta da pesquisa com os colaboradores, que pode ser considerada uma lacuna, para identificação das competências essenciais do Colégio, que uma vez identificadas poderão definir a estratégia de GC e elaborar e implementar seu plano. Entretanto, é possível, por meio da própria ferramenta OKA, repetir a aplicação do questionário, daqui a um ano, e avaliar qual foi a evolução das iniciativas de GC na gestão escolar do Colégio Formação.

Para as futuras pesquisas, é importante considerar também a introdução de novos métodos de coleta e análise de dados. Como é sabido, nenhum método encerra em si mesmo todas as potencialidades de análise para todas as situações.

Vale destacar, que a viabilidade do estudo depende da alta gestão, em fazer a relação da identificação das prioridades das práticas de GC mais relevantes que facilitará o monitoramento da estrutura do Colégio Formação e seus profissionais no desenvolvimento das melhores práticas de Gestão do Conhecimento.

Este trabalho colabora para ampliação do conhecimento do Colégio sobre si mesmo e enfatiza a necessidade da Alta Gestão e dos colaboradores que são responsáveis por processos de mudanças organizacionais na criação de indicadores que facilitem o compartilhamento das práticas de Gestão do Conhecimento nas atividades do Colégio Formação. Conclui-se que os resultados da pesquisa apresentam evidências consistentes das dimensões do conhecimento e orientações para o desenho do plano de GC e sugere-se por meio da gestão por processos uma metodologia compatível para modelagem adaptada à realidade do Colégio e desenvolvida com o apoio de outras ferramentas e abordagens.

\title{
THE SOCIO CONSTRUCTIVIST APPROACH IN SCHOOL MANAGEMENT: A PARTNERSHIP FOR THE CONSTRUCTION OF KNOWLEDGE - CASE STUDY IN AN EDUCATIONAL INSTITUTION IN RECIFE
}

\begin{abstract}
The present article deals with the theme of Knowledge Management and emphasizes the importance of its application in a School in Recife, which uses the approach in the process of teaching and learning according to socio-constructivism. Through a case study, we tried to create indicators for the creation of a Community of Practice in the institution, which already works elements geared towards Knowledge Management, by taking into account tacit knowledge. The article aimed to verify the current situation of the educational institution and from the analysis of data collected applying the method Organizational Knowledge Assessment, and the three dimensions (people, processes and systems) reveal a partnership for the construction of knowledge. The results of the research showed that it was possible to visualize the strengths and weaknesses for the implementation of a plan of Knowledge Management, related to work processes. The application of such plan,demands from senior management levels commitment to the plan, awareness of the importance of deploying the tools of knowledge management not only in the sphere of practices, but also in the educational context, acting directly in the diagnostic process with collaborators.We conclude that the results of the research provide strong evidence of the dimensions of knowledge and guidance for the design of a Knowledge Management plan.
\end{abstract}

Keywords: : Knowledge Management. Knowledge. Socio-constructivist learning. Education. 


\section{REFERÊNCIAS}

D'ÁVILA, Cristina. Por uma didática colaborativa no contexto das comunidades virtuais de aprendizagem. In: SANTOS, Edméa; ALVES, Lynn (Org.). Práticas pedagógicas e tecnologias digitais. Rio de Janeiro: E-papers, 2006. p. 91-100.

DAVENPORT, T. H.; PRUSAK, Laurence. Conhecimento empresarial: como as organizações gerenciam o seu capital intelectual. 15. ed. Rio de Janeiro: Campus, 2003.

DRUZIANI, Cássio Frederico Moreira et al. Sistemas de Gestão do Conhecimento aplicados à Educação: uma revisão sistemática de literatura. [2011]. Disponível em:<http://www.inf.unioeste.br/enined/anais/artigos_ enined/A48.pdf>. Acesso em: 28 maio 2014.

ESTEVES, Vera Vergara; PEREIRA, Wally Chan; SIANO, Lucia Maria França. Uma competência emergente na gestão escolar: a animação cultural. Ensaio: aval. pol. públ. Educ., [online],v. 13, n. 47, p. 169-180, 2005. http://dx.doi. org/10.1590/S0104-40362005000200004.

FONSECA, A. F. Organizational Knowledge Assessment Methodology. Washington, DC: World Bank Institute, 2006.

GAIA, Lilian Fátima; BENTO, Karina Gomes dos Reis. O papel do Setor de Recursos Humanos na Gestão do Conhecimento em uma empresa do Ramo automotivo. [2011]. Disponível em:<http://www.sbgc.org.br/ kmbrasil2011/anais/pdf/TC89.pdf>Acessoem: 28 maio 2014.

GIL, Antônio Carlos. Método e técnicas de pesquisa social. 5. ed. São Paulo: Atlas, 2006.

GOZZI, Marcelo Pupim. O Processo de Gestão do Conhecimento em Comunidades Virtuais de Aprendizagem. Perspectivas em Gestão \& Conhecimento, João Pessoa, v. 2, n. 2, p. 3-14, jul./dez. 2012. Disponível em <http:// periodicos.ufpb.br/ojs2/index.php/pgc.>Acesso em: 04 jun. 2014.

KIDWELL, J. J.; LINDE, K. M.; JOHNSON, S. Applying corporate knowledge management practices in higher education. Educause Quarterly, [online], v. 4, n. 4, p. 28-33, 2000.Disponível em<https://net.educause.edu/ir/ library/pdf/EQM0044.pdf>. Acesso em: 05 jun. 2014.

KURTZ, Diego Jacob. Seminários de Pesquisa 2010: Proposta de Teses ou Dissertação. [2010]. Disponível em: <http://kern.ispeople.org/egc/seminarios/20_M_GC.pdf>. Acesso em: 14 ago. 2014.

KURTZ, Diego Jacob. Fluxo de conhecimento Interorganizacional: aspectos relacionados à cadeia suinícola brasileira. Dissertação (Mestrado) - Universidade Federal de Santa Catarina, Florianópolis, 2011.

LINS, Sérgio. Transferindo conhecimento tácito: uma abordagem construtivista. Rio de Janeiro: E-papers, 2003.

NONAKA, I.; TAKEUCHI, H. Criação de conhecimento na empresa: como as empresas japonesas geram a dinâmica da inovação. Rio de Janeiro: Campus, 1997.

PIAGET, Jean. Problemas de psicologia genética. Petrópolis: Vozes, 1972.

RODRIGUES, D. Educação inclusiva: as boas notícias e as más notícias. In: RODRIGUES, D. (Org.). Perspectivas sobre a inclusão: da educação à sociedade. Porto: Porto Editora, 2003. p. 89-101.

ROWLEY, J. From learning organization to knowledge entrepreneur. Journal of Knowledge Management, [online], v. 4, n. 1, p.7-15, 2000. Disponível em:<http://emeraldinsight.com/toc/jkm/4/4> Acesso em: 03 mar.2015.

SCHNEIDER, H. N. TIC e Educação: pontos impactantes. Revista TI\&NSergipe, Aracaju, n. 13, maio/jun. 2013.

SORDI, José Osvaldo de. Gestão por Processos: uma abordagem da moderna administração. 2. ed. São Paulo: Saraiva, 2008. 
TERRA, J. C.C; GORDON, C. Portais Colaborativos: A revolução na gestão do conhecimento. São Paulo: Elsevier, 2002.

TEIXEIRA FILHO, Jayme. Recursos Humanos na Gestão do conhecimento.[2000]. Disponível em: <http://tupi. fisica.ufmg.br/michel/docs/Artigos_e_textos/Ciencia_da_informacao/RH_na_GC.pdf>.Acesso em: 28 maio 2014.

TRIVIÑOS, A. N. S. Introdução à pesquisa em ciências sociais: a pesquisa qualitativa em educação. São Paulo: Atlas, 1990.

VASCONCELLOS, Patricia Ribeiro; OLIVEIRA, Eloíza da Silva Gomes de. Processos Interacionais de Construção de Conhecimentos em Ambientes Virtuais de Aprendizagem. [2011]. Disponívelem:<http://www.inf. unioeste.br/enined/anais/artigos_enined/A7.pdf>. Acesso em: 12 ago. 2014.

VERGARA, S. C. Projetos e relatórios de pesquisa em administração. 11. ed. São Paulo: Atlas, 2007.

VYGOTSKY, Lev S. A formação social da mente: o desenvolvimento dos processos psicológicos superiores. 3. ed. São Paulo: Martins Fontes, 1989. (Coleção Psicologia e Pedagogia. Nova Série).

VON KROGH, G.; NONAKA, I.; ABEN, M. Making the Most of Your Company's Knowledge: A strategic Framework. Long Range Planning, Pergamon, v. 34, p. 421-439, 2001. Disponível em: <https://ai.wu.ac.at/ kaiser/birgit/ Nonaka-Papers/Making-the-most-of-our-companys-knowledge.Strategic-framework-2001.pdf>. Acesso em: 12 ago. 2014.

WENGER, E. Communities of Practice. Learning as a social system. The Systems Thinker, Westford, MA, v. 9, n. 5, p. 1-16, June/July 1998 .Disponível em: <http://homepages.abdn.ac.uk/n.coutts/pages/Radio4/Articles/ wenger2000.pdf>. Acesso em: 27 mar. 2014. 